
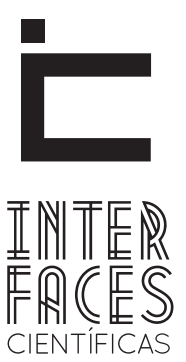

SAÚDE E AMBIENTE

\title{
TÉCNICAS DE MELHORAMENTO GENÉTICO EM BOVINOS PARA O AUMENTO NA PRODUÇÃO DE LEITE
}

\author{
Edineide da Silva Machado \\ Luciana Oliveira $^{1}$ \\ Thaís Andrade de Lima ${ }^{1}$
}

\author{
João Marcos Cézar ${ }^{1}$ \\ Luciano Sousa Teixeira²
}

\section{RESUMO}

O objetivo nesta revisão é mostrar as principais técnicas utilizadas na área de melhoramento genético na reprodução animal e como estes podem afetar a eficiência reprodutiva e na produtiva de leite. Com o conhecimento dos mecanismos envolvidos no controle da fisiologia reprodutiva, em níveis endócrino, celular e molecular, foi possível o desenvolvimento das biotecnias reprodutivas, destacando-se a Inseminação Artificial em Tempo Fixo, que tem sido utilizada em larga escala, por permitir a multiplicação de animais superiores geneticamente, aumentar a taxa de natalidade e ser eficaz no ajuste da estação reprodutiva notadamente em pecuária de leite. Outras biotecnias, como a Inseminação Artificial, Transferência de Embriões, Produção in
Vitro de Embriões, também são fundamentais no desenvolvimento de pesquisas de ciência básica, medicina e preservação animal. São apresentados, também, os principais fatores de manejo reprodutivo nutricional e sanitário que afetam a produtividade da pecuária leiteira. Contudo, o incentivo às pesquisas é fundamental para que estas biotecnias sejam aprimoradas e continuem auxiliando o desenvolvimento da pecuária nacional.

\section{PALAVRAS-CHAVE}

Melhoramento Genético/Bovinos. Inseminação Artificial. Transferência de Embriões. Produção In Vitro de Embriões. Inseminação em Tempo Fixo. 


\section{ABSTRACT}

The purpose of this review is to show the main techniques used in the area of genetic improvement in animal reproduction and how these can affect the reproductive efficiency and milk production. With the knowledge of the mechanisms involved in control of reproductive physiology in endocrine levels, cellular and molecular, it was possible the development of reproductive biotechnology, especially the fixed-time artificial insemination, which has been used on a large scale, by allowing the multiplication of genetically superior animals to increase the birth rate and be effective in the setting of the breeding season especially in dairy cattle. Other biotechnology, such as artificial insemination, embryo transfer, in vitro production of embryos, is also critical in the development of basic science research, medicine and animal conservation. Furthermore, presents the main factors of nutritional and reproductive management of health that affects the productivity of dairy cattle. However, the incentive to research is essential for this biotech enhancing and continues helping the development of the national livestock.

\section{KEYWORDS}

Breeding / Cattle. Artificial Insemination. Embryo Transfer in vitro production of embryos. Fixed-time insemination.

\section{INTRODUÇ̧̃̃O}

A reprodução animal constitui-se num dos fatores de maior importância que afeta diretamente a eficiência e a rentabilidade dos sistemas produtivos (NEVES, MIRANDA, TORTORELLA, 2010).

\section{RESUMEN}

El objetivo de esta revisión es mostrar las principales técnicas utilizadas en el campo de la mejora genética en la cría de animales y cómo estos pueden afectar la eficiencia reproductiva y producción de leche. Con el conocimiento de los mecanismos implicados en el control de la fisiología reproductiva en endocrina, los niveles celulares y moleculares, era posible el desarrollo de biotecnias reproductivos, destacando la inseminación artificial, que se ha utilizado en gran escala, por lo que permite la multiplicación de animales genéticamente superiores para aumentar la tasa de natalidad y ser eficaz en el ajuste de la temporada de cría, especialmente en el sector lechero. Otros biotecnias como la inseminación artificial, transferencia de embriones, la producción de embriones in vitro, también son fundamentales en el desarrollo de la investigación en ciencia básica, la medicina y la preservación de mascotas. También se presentan los principales factores de nutrición y control de la salud reproductiva que afectan a la productividad de las vacas lecheras. Sin embargo, el incentivo a la investigación es vital para que estas biotecnias sean potencializadas y puedan continuar ayudando al desarrollo de la ganadería nacional.

\section{PALABRAS CLAVE}

Reproducción / Ganado.; La Inseminación Artificial. Transferencia de Embriones. La Producción de Embriones In Vitro. La Inseminación.

Com os novos rumos do comércio ao nível nacional e internacional, e o aumento da competitividade na busca de novos mercados, a produção de alimentos, tende a buscar saídas para um crescimento em quan- 
tidade e qualidade. Dessa forma, o estudo do melhoramento genético e suas técnicas utilizadas, são de grande importância para o progresso dessas atividades (COSTA, 2009).

O melhoramento animal é o resultado da aplicação de técnicas que alteram as frequências dos genes, visando o aumento da produtividade, em determinado ambiente. Apesar de ter sua fundamentação teórica desenvolvida há alguns anos, o melhoramento genético, recentemente tem recebido grandes contribuições que são as principais responsáveis tanto pela expansão quanto pelos progressos genéticos que têm sido observados nas mais diferentes espécies de animais domésticos explorados comercialmente, já que o mercado exige que aconteçam melhorias (COSTA, 2009).

Apesar de o Brasil possuir o maior rebanho bovino comercial do mundo. Em 2003 esse demonstrou baixa eficiência reprodutiva com taxa de prenhez em torno de $60 \%$ (SILVA, 2007). 0 melhoramento genético, em bovinos vem sendo usado para um aumento na produção animal, pois esse aumenta consideravelmente o número de partos, aumentando assim à produção de fêmeas e consequentemente a produção de leite (COSTA, 2009).

Esse melhoramento pode ser feito com varias técnicas, entre elas: inseminação artificial (IA), Inseminação artificial em tempo fixo (IATF), transferência de embriões (TE), produção in vitro de embriões (PIVE), que serão tratadas neste artigo.

O propósito desta revisão é apresentar as técnicas de melhoramento genético e mostrar dentre essas qual a melhor a ser usada na eficiência da produção de leite.

\section{INSEMINAÇÃO ARTIFICIAL [IA]}

A primeira inseminação artificial, em mamíferos, foi realizada em 1780, por Lazzaro Spalanzani, em um cachorro (PEREIRA, 2009).
O principal objetivo da IA é promover melhoria no genótipo do rebanho por meio da utilização de sêmen de bons reprodutores e de elevada capacidade reprodutiva e que possam transmitir suas características para suas proles. A técnica de IA consiste na introdução do sêmen no interior da vagina e depósito deste material no corpo do útero, da fêmea a ser fertilizada. A IA deve ser realizada, na vaca, na fase metaestro do ciclo estral, que é o momento mais favorável para o encontro entre os espermatozoides e o óvulo (PEREIRA, 2009).

O sucesso da inseminação artificial depende, também, do máximo cuidado de higiene, assim como da hora da realização da inseminação. 0 melhor momento para realizar a inseminação é quando a fêmea não monta mais nas companheiras do rebanho, e não se deixa montar nem mesmo pelo rufião (BRITO, et al, 2007).

O uso da IA é muito simples, é a técnica mais antiga e de baixo custo, porém é de difícil manejo e encontram-se problemas quanto à visualização do estro (NEVES, MIRANDA, TORTORELLA, 2010). Todas as fêmeas têm que ciclar para serem inseminadas, fazendo com que 0 período desta estação de IA seja no mínimo de um ciclo estral. Dessa forma, é necessária que haja mão de obra disponível diariamente para o controle do estro e para inseminar as fêmeas que ciclaram naquele período (BRITO, et al, 2007).

\section{INSEMINAÇÃO ARTIFICIAL EM TEMPO FIXO CIATF]}

Surgiu para suprir a carência, de observação de estro, da IA. Com essa técnica iniciou-se a pesquisa com o uso de hormônios para controlar o estro e ovulação destas fêmeas. Dessa forma, a IATF é uma opção de manejo capaz de eliminar a necessidade de detecção de estros (PERREIRA, 2009).

Nessa técnica (IATF), emprega-se uma sequência de tratamentos para sincronizar a ovulação. A sincronização da ovulação para IATF possibilita que as vacas 
sejam inseminadas e se tornem gestantes no inicio da estação de monta, diminuindo o período de serviço e aumentando a eficiência reprodutiva do rebanho. Com um bom sincronismo, há um controle preciso do estro e não precisa detectar o estro (PERREIRA, 2009).

Nesse processo são usados os seguintes hormônios: progesteronas (P4), Benzoato de estradiol (BE), prostaglandina (PGF2 $\alpha$ ), gonadotrofina coriônica (eCG), hormônio liberador de gonadotrofinas $(\mathrm{GnRH})$ (NEVES, MIRANDA, TORTORELLA, 2010).

Os tratamentos mais difundidos utilizam a combinação de progesterona ( $\mathrm{P} 4)$ e benzoato de estradiol (BE) ou hormônio liberador de gonadotrofinas (GnRH) para conseguir o controle da ovulação. O tratamento com este estrógeno promove a liberação de um pico de $\mathrm{LH}$, dentro de um intervalo de 16 a 30 horas. Já a administração de $\mathrm{GnRH}$ induz um pico de LH que se inicia logo após sua aplicação em torno de 15 minutos (NEVES, MIRANDA, TORTORELLA, 2010).

\section{TRANSFERÊNCIA DE EMBRIÕES (TE]}

A TE é uma biotecnia utilizada para recolher embriões de uma fêmea doadora e transferi-los para uma fêmea receptora completando o período de gestação (HENRIQUE, 2007)

Sua importância básica para a produção animal consiste na possibilidade de uma fêmea produzir um número de descendente muito superior ao que seria possível obter fisiologicamente durante sua vida reprodutiva (TANEJA et al., 2000). Sendo assim, essa técnica se trata de uma multiplicação acelerada dos descendentes, de fêmeas consideradas superiores (PASA; ALVAREZ, 2008)

Nesse processo é preciso de fêmeas doadoras e receptoras. A doadora será submetida a tratamento que irá fazer essa sofrer múltiplas ovulações. Esses óvulos se fecundados serão avaliados uma semana após e os "melhores" embriões serão transferidos para fêmea receptora (COSTA, 2009; PASA, 2008).
De uma mesma vaca (doadora) podem ser feitas varias coletas durante um ano. Para uma excelente produtividade do embrião é importante observar o estro tanto das doadoras quanto das receptoras. Tem que existir um sincronismo de estro entra a doadora e a receptora, sendo que pode ter uma flexibilidade de um dia (COSTA, 2009; PASA, 2008).

A criopreservação foi de fundamental importância para a TE, com uma produção de embriões maior do que a necessária para a transferência, possibilitando assim o transporte de embriões congelados (NEVES, MIRANDA, TORTORELLA, 2010).

\section{PRODUCÕ̃ES IN VITRO DE EMBRIÕES BOVINOS (PIVE]}

Segundo Brandão (2006), "A produção in vitro de embriões em muito evoluiu nos últimos anos, saindo de uma condição de método de pesquisa e estudo de embriologia, para tornar-se uma técnica viável de utilização comercial”.

De acordo com a EMBRAPA (2004), a técnica de PIVE é a união do gameta masculino e o gameta feminino, realizada em um laboratório 0 objetivo dessa técnica é produzir embriões bovinos em larga escala, com maior qualidade genética e preços mais acessíveis, prontos para serem transferidos ou conservados.

A PIVE vem sendo usada como um método alternativo ou complementar da TE (COSTA, 2009; GARCIA, AVELINO, VANTINI, 2008).

A PIVE além de aumentar a produção de bezerros em um curto período de tempo e de poder obter animais com um ganho genético em carne ou leite traz outros benefícios a pesquisa e a produção, como a formação de banco de ovócitos criopreservados, onde por meio do ovócito congelado é possível no futuro regenerar raças em extinção (MARTINEZ et al, 2007). 


\section{METODOLOGIA}

Este estudo foi construído por meio do levantamento de dados encontrados na literatura já existente, foram selecionados artigos publicados nos últimos cinco anos. Estas pesquisas foram realiza-

\section{DISCUSSÃO}

As principais vantagens observadas na IA são: a inseminação de várias vacas, melhorando a utilização do reprodutor; intensificação a seleção já que se usam poucos touros; diminuição do custo da reprodução; e não há limites para uso do sêmen (PERREIRA, 2009).

Não é fácil descobrir o exato momento do estro da vaca. Por isso, conclui-se que a IA tem algumas limitações, é necessário descobrir o exato momento do estro; Inseminação deve ocorrer num curto espaço de tempo (PERREIRA, 2009).

Devido a estas e outras dificuldades, muitas propriedades de pecuária ainda não implantaram o uso da IA. Segundo Barbosa (2008) apenas 6\% do total de fêmeas em reprodução são inseminadas. Sendo apenas 3,9 das fêmeas dos rebanhos de corte e 13,7 das fêmeas os rebanhos leiteiros (PERREIRA, 2009).

Segundo SILVA (2007) a Inseminação Artificial em Tempo Fixo (IATF) é uma nova técnica que permite o uso em massa da IA, por não envolver a observação de cio e abranger grande número de animais inseminados em um mesmo dia. Tem sido proposto das no Scielo e no Google acadêmico onde foram consultados artigos originais e de revisão sobre o tema para um melhor conhecimento do assunto abordado nessa revisão.

que a IATF é uma opção de manejo capaz de eliminar a necessidade de detecção de estros, produzindo resultados iguais ou superiores a IA convencional. Além disso, IATF é uma tecnologia que permite emprenhar um grande número de vacas em um único dia de inseminação (PERREIRA, 2009).

Algumas vantagens observadas na Transferência de Embriões (TE) são: um aceleramento e maior precisão no processo de seleção animal; proporciona por meio do congelamento de embriões o transporte internacional de germoplasma sem o risco de transmissão de doenças; conservação de raças em perigo de extinção, dentre outros aspectos.

Na Produção in vitro de Embriões algumas vantagens podem ser observadas como: um aumento de produção de bezerros em um curto período de tempo; obtenção de mais animais com um ganho genético em carne ou leite; uma formação de banco de ovócitos criopreservados; é possível uma recuperação de material genético em vacas que apresentam problemas reprodutivos que foram adquiridos; diminuição do intervalo entre as gerações a partir da produção de embriões em fêmeas imaturas. 


\section{CONSIDERAÇ̃̃ES FINAIS}

Observou-se, por meio deste estudo, que a utilização de biotecnologias como a transferência de embriões (TE), e a produção in vitro (PIVE), apresentam muitas vantagens, como o aumento dos índices reprodutivos em fêmeas bovinas.

Garantindo, assim, um melhor aproveitamento das fêmeas leiteiras de qualidade, produzindo descendentes de igual valor genético, podendo influenciar em um maior controle de doenças e escolha do sexo do produto, ambas as técnicas contribuem para um melhoramento genético em gado leiteiro. Bem como um aumento na produção de bezerros, da vida útil do animal, garantindo maior lucratividade além de contribuir para o estudo embriológico.

\section{REFERENCIAS}

NEVES JP, MIRANDA KL, TORTORELLA RD. Progresso Científico em reprodução na primeira década do século XXI. Rev. Bras. Zoot., v. 39. 2010, p. 414-418.

Costa MA. 0 uso das técnicas de transferência de embriões e fertilização in vitro em bovinos da raça gir, na associação dos produtores rurais da comunidade de vista alegre-aprovista. Cáceres- Mato Grosso: Universidade do Estado de Mato Grosso; 2009, 10:14-17.

Ferraz JBS, Eler JP. Parceria publica x privada no desenvolvimento de pesquisa em melhoramento genético animal. Rev. Bras. de Zootec., v. 39, 2010; 216.

Pereira VC. Inseminação artificial e sincronização de cio de bovinos. Porto Alegre: Universidade Federal do Rio Grande do Sul, 2009; 14-18.

Brito LG, Salman AKD, Gonçales MAR, Figueiró MR. Cartilha para o produtor de leite de Rondônia. Embrapa; Porto Velho (RO), 2007, 35-36.

Pasa C. Transferência de embriões em bovinos. Biodiversidade. FAMEV - UFMT, v. 7, n. 1, 2008, p. 67-68.

Alvarez $\mathrm{RH}$. Fatores determinantes do sucesso de um programa de transferência de embriões em bovinos. 2008. Disponivel em: <http://www.infobibos.com/ Artigos/2008_1/embrioes/index.htm>. Acesso em: 8 jun. 2011.

Silva PR. Transferência de embriões em bovinos, superovulação, colheita, seleção e implantação dos embriões. Rio de Janeiro: Universidade Castelo Branco, 2007.

Prado FR de A. Protocolos de superovulação em vacas da raça gir quanto ao número de estruturas totais, embriões viáveis e degenerados [Dissertação]. Botucatu (SP): Universidade Estadual Paulista, 2006.

Brandão DO. Produção In Vitro de embriões: cultivo de embriões pós-eclosão e criopreservação de meios prontos para uso [tese]. Brasília (DF): Universidade de Brasília; 2006.

Garcia JM, Avelino KB, Vantini R. Estado da arte da fertilização de bovinos. Jaboticabal: FCAV/ UNESP, 2008. 
Recebido em: 10 de Agosto de 2013 Avaliado em: 30 de Agosto de 2013 Aceito em: 22 de Novembro de 2013
1 Graduados em Ciências biológicas pela Universidade Federal de Sergipe.

2 Graduado em Educação física pela Universidade Tiradentes. E-mail: lucianoteixeira_2@hotmail.com 


\section{EDITORAÇÃO ELETRÔNICA}

\section{Projeto Gráfico}

Edilberto Marcelino

Capa e Diagramação

Igor Bento

\section{Produção}

Cordenação de Tecnologias Educacionais - CTE

Núcleo de Ensino a Distância - NEAD

\section{IMPRESSÃO}

Gráfica Gutemberg

Universidade Tiradentes

\section{TIRAGEM}

200

\section{TIPOGRAFIA}

Signika

Bebas Neue

PAPEL

\section{Capa}

Papel Supremo $250 \mathrm{~g} / \mathrm{m}^{2}$

Miolo

Papel Offset $90 \mathrm{~g} / \mathrm{m}^{2}$ 